\title{
Article
}

\section{An Investigation of Modelling Accuracy Needs for Urban Design Flood Estimation}

\author{
James E Ball 1* \\ 1 School of Civil \& Environmental Engineering, University of Technology Sydney; james.ball@uts.edu.au \\ * Correspondence: james.ball@uts.edu.au
}

\begin{abstract}
Flood Management remains a major problem in many urban environments. Commonly, catchment models are used to generate the data needed for estimation of flood risk; event-based and continuous-based models have been used for this purpose. Use of catchment models requires calibration and validation with a calibration metric used to assess the predicted catchment response against the recorded catchment response. In this study, a continuous model based on SWMM using the Powells Creek catchment as a case study is investigated. Calibration of the model was obtained using 25 selected events from the monitored data for the catchment. Assessment of the calibration used a normalised peak flow error. Using alternative sets of parameter values to obtain estimates of the peak flow for each of the selected events and different accuracy criteria, the best datasets for each of the accuracy criteria were identified. These datasets were used with SWMM in a continuous simulation mode to predict flow sequences for extraction of Annual Maxima Series for an At-Site Flood Frequency Analysis. From analysis of these At-Site Flood Frequency Analyses, it was concluded that the normalised peak flow error needed to be less than $10 \%$ if reliable design flood quantile estimates were to be obtained.
\end{abstract}

Keywords: urban; flood; calibration; model; SWMM; continuous

\section{Introduction}

An increasing portion of the world's population now lives in urban environments; [1] estimated that $55 \%$ of the world's population currently live in urban areas and that, by 2050 , that portion will have grown to $68 \%$. Management of water in these environments to satisfy the needs of this increasing urban population is a problem that many managers are encountering. Of the many water management issues in urban catchments, estimation of the magnitude and likelihood of flood events is a common issue. There are many different issues requiring design flood estimation; see, for example, [2], [3], and [4] who present different aspects of the need to estimate design floods in urban environments. Nonetheless, the fundamental need for all issues is data enabling estimation of the magnitude and likelihood of flood events.

Data for estimating flood quantiles (i.e. the flood magnitude and its likelihood) can be obtained from catchment monitoring or catchment modelling with these data sources being complementary rather than competitive. Numerous alternative approaches have been developed for determination of the flood risk; [5] discusses these approaches and categorises the approaches considered as being either "analysis of streamflow data" or "rainfall based"; herein, similar categories are used although they are referred to as "catchment monitoring approaches" and "catchment modelling approaches".

The absence of monitored data in many urban environments has resulted in the necessary data being obtained predominantly from the use of catchment modelling. Two alternative approaches for catchment modelling have been developed (see, for example, [6]). Irrespective of the approach used, the application of catchment modelling requires the calibration and validation of the catchment model. Many different techniques have been proposed for calibration and validation of catchment models; these techniques include Bayesian (e.g. [7], [8]), Direct Search (e.g. [9]), Genetic Algorithms (e.g. [10], [11]), Shuffled Complex Evolution (e.g. [12]), and Particle Swarm Optimisation (e.g. [13]). 
Consistent among these techniques is the need to define a calibration metric suitable for defining accuracy of the predicted catchment response. Discussion of calibration metrics can be found in [14], [15], and [16]). These discussions have focussed on the calibration metrics and have rarely addressed the related question of what value of calibration metric needs to be achieved for prediction of reliable catchment response data. This question is addressed herein through consideration of the required accuracy in prediction of single event hydrograph peak flows and the subsequent use of the parameter values for prediction of reliable flow sequences suitable for an At-Site Flood Frequency Analysis in an urban environment.

\section{Powells Creek Catchment}

\subsection{Catchment Description}

The Powells Creek catchment, sometimes referred to as the Strathfield catchment, is an 841ha catchment situated $10 \mathrm{~km}$ west of Sydney's central business district. The location of this catchment is shown in Figure 1. The catchment lies within the Sydney suburbs of Homebush West, North Strathfield, Rookwood and Strathfield, and is administered by the local government areas of Strathfield, Canada Bay and Auburn. The drainage network comprises a closed piped system that opens out to a lined channel and then into the Parramatta River. The main open channel was established in 1892 ([17]) while the closed pipe system was established in the 1920's.

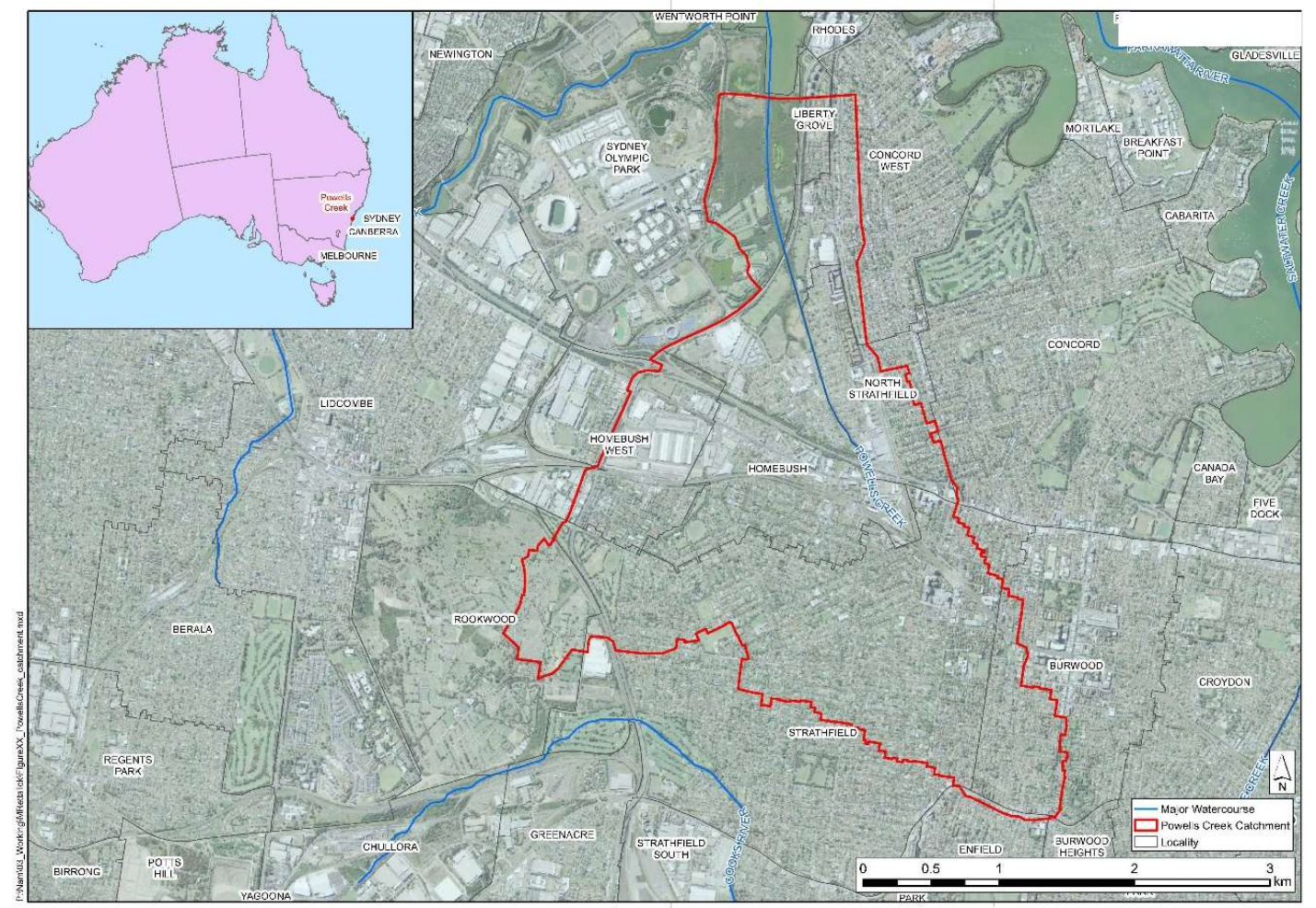

Figure 1. Powells Creek Catchment

Shown in Table 1are the types and proportions of alternative land uses within the catchment as outlined by [17]. In general, the catchment is classified as low-lying, with gentle slopes between $4 \%$ and $5.5 \%$. The maximum elevation is $40 \mathrm{~m}$ AHD while the minimum elevation is governed by the tidal regime of the Parramatta River. 
Table 1. Land Use in the Powells Creek Catchment (after Meutia, 2002)

\begin{tabular}{ccc}
\hline LAND USE & $\begin{array}{c}\text { AREA } \\
(\mathrm{ha})\end{array}$ & $\begin{array}{c}\text { PROPORTION } \\
(\%)\end{array}$ \\
\hline Residential & 504.7 & 60.0 \\
Industrial & 40.5 & 4.8 \\
Commercial & 27.1 & 3.2 \\
Open Space & 61.1 & 7.3 \\
Special Use & 208.1 & 24.7 \\
\hline
\end{tabular}

\subsection{Available Data}

The School of Civil and Environmental Engineering at The University of New South Wales operated a gauging station on the main Powells Creek Stormwater Channel during the period 1958 to 2005. The catchment area draining to this gauging station consists of only $2.3 \mathrm{~km}^{2}$ of the total catchment area. In addition, rainfall was monitored at the centroid of the monitored catchment and, for a short period, at the gauging station itself.

Table 2. List of Events

\begin{tabular}{|c|c|c|c|c|}
\hline Date & $\begin{array}{c}\text { Rainfall } \\
\text { (mm) }\end{array}$ & $\begin{array}{l}\text { Flow } \\
\left(\mathrm{m}^{3} / \mathrm{s}\right)\end{array}$ & $\begin{array}{c}\text { Duration } \\
\text { (hrs) }\end{array}$ & $\begin{array}{l}\text { Flow AEP }{ }^{1} \\
\text { (1 in years) }\end{array}$ \\
\hline May 1981 & 87.0 & 9.025 & 63 & 0.40 \\
\hline October 1981 & 61.5 & 14.31 & 21 & 1.70 \\
\hline January 1982 & 19.5 & 8.908 & 4 & 0.40 \\
\hline March 1982 & 44.0 & 18.79 & 4 & 1.95 \\
\hline March 1983 & 113.3 & 21.12 & 78 & 4.19 \\
\hline November 1984 & 179.5 & 21.16 & 5 & 4.67 \\
\hline October 1985 & 16.2 & 11.89 & 3 & 1.51 \\
\hline February 1986 & 57.5 & 19.68 & 4 & 3.79 \\
\hline December 1987 & 34.8 & 11.30 & 16 & 1.27 \\
\hline 12 April 1988 & 53.4 & 8.656 & 18 & 0.37 \\
\hline 28 April 1988 & 328.9 & 22.36 & 59 & 5.29 \\
\hline July 1988 & 120.3 & 22.90 & 38 & 6.09 \\
\hline April 1989 & 17.5 & 7.742 & 4 & 0.30 \\
\hline 6 March 1990 & 23.1 & 10.14 & 5 & 0.47 \\
\hline 18 March 1990 & 55.2 & 22.94 & 5 & 7.18 \\
\hline July 1990 & 152.3 & 10.30 & 74 & 0.48 \\
\hline February 1992 & 321.6 & 16.68 & 50 & 2.28 \\
\hline January 1993 & 16.0 & 9.516 & 3 & 0.44 \\
\hline April 1994 & 95.6 & 15.16 & 40 & 1.57 \\
\hline 2 March 1995 & 31.4 & 12.24 & 14 & 0.70 \\
\hline 15 March 1995 & 57.2 & 5.282 & 25 & 0.17 \\
\hline September 1995 & 153.2 & 13.16 & 22 & 1.16 \\
\hline January 1997 & 52.2 & 6.871 & 32 & 0.24 \\
\hline June 1997 & 18.0 & 6.588 & 4 & 0.21 \\
\hline October 1997 & 46.0 & 5.706 & 9 & 0.18 \\
\hline
\end{tabular}


From this data, 25 events in the documented period post 1980 were extracted for calibration of the catchment model. Details of these events are presented in Table 2 and in Figure 2 where the extracted events are plotted on a flood frequency diagram. As shown in that figure, the largest recorded events occurred prior to 1980. Selection of events only post 1980 was related to the availability of reliable precipitation data over the catchment. The lack of these larger events will be reflected in the estimated flood quantiles obtained from the At-Site Flood Frequency Analyses undertaken as part of this study.

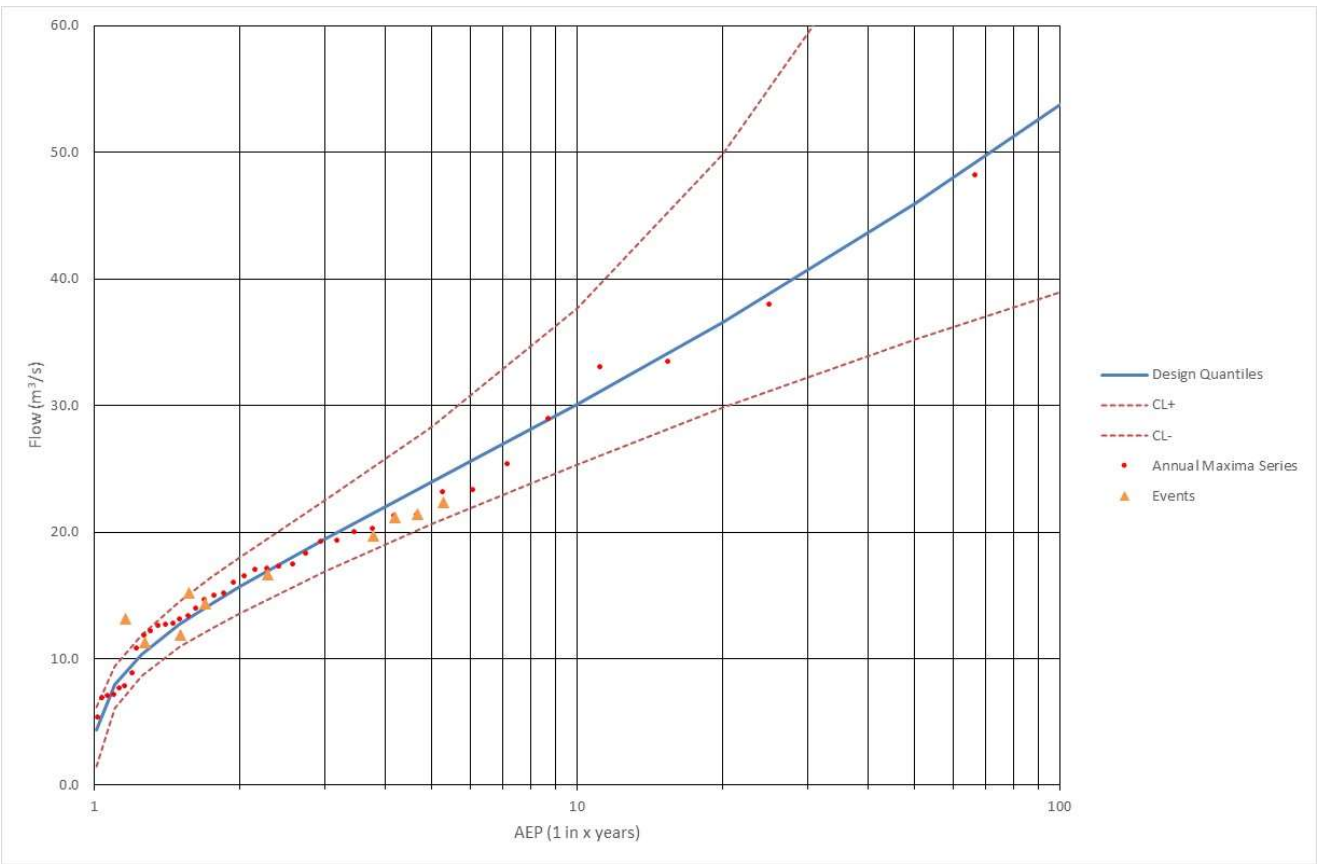

Figure 2. Events shown on the FFA for the Gauging Station

\subsection{Catchment Model}

There are numerous alternative software systems suitable for process-based modelling of existing and potential urban catchments. After considering these alternatives, the SWMM system ([18]) was used herein for data generation. This model has received extensive application; see, for example, [19] and [20] for recent applications.

SWMM is a physically distributed catchment modelling system consistent with the conceptual components of a catchment modelling system proposed by [21]; these components are:

- Generation - this component of the modelling system is concerned with spatial and temporal models necessary to convert point data into spatial-temporal data. An example is the conversion of point rainfall records into spatial rainfall models over the catchment at suitable resolution.

- Collection - the component of the model where those processes concerned with the generation of runoff are dominant. This is the hydrologic component of the modelling system.

- Transport - the component of the model where the processes concerned with the movement of water through the drainage system are dominant. This is the hydraulic component of the modelling system.

- Disposal - the component of the modelling system concerned with the discharge of water from the drainage system into receiving waters.

As a comprehensive catchment modelling system, SWMM can be operated in either an event mode, or a continuous mode. For model calibration, SWMM was operated in event mode; in other words, the model was calibrated to the 25 events presented in Table 2. However, for prediction of 
design flood flows, SWMM was operated in continuous mode to predict the data used in the At-Site Flood Frequency Analysis.

As a distributed catchment modelling system, application of SWMM requires users to deal with numerous spatially variable parameters. These spatially variable parameters were classified into two categories, namely measured parameters and inferred parameters, by [22]. The parameters that are measured (for example, the subcatchment areas, the length and slope of open channels and pipes) are assumed to be error free whereas the inferred parameters cannot be measured and are estimated during the calibration process.

\section{Model Use}

\subsection{Model Calibration}

For construction of the catchment model, the Powells Creek catchment was divided into 103 subcatchments and a similar number of channels. SWMM has the capacity for each subcatchment and channel to have unique parameter values. This capacity was utilised during calibration of the model. For the purposes of calibrating the SWMM model of Powells Creek used in this study, the parameters considered are shown in Table 3.

Table 3. Parameters considered during model calibration.

\begin{tabular}{cc}
\hline Subcatchment Parameter & Channel Parameter \\
\hline Subcatchment Width & \\
Subcatchment Slope & \\
Imperviousness & Conduit roughness \\
Surface roughness (impervious and pervious) & \\
Depression storage (impervious and pervious) & \\
Impervious area with no depression storage & \\
Infiltration parameters (maximum rate, minimum rate, & \\
infiltration decay, and infiltration recovery rate) &
\end{tabular}

A previously calibrated model of Powells Creek was available from [17]. These parameter values were used as the median of the search space considered. Using a range of $\pm 50 \%$ of the values obtained by [17], 1000 alternative sets of parameter values were developed assuming parameter values were uniformly distributed within the search space; in other words, all parameter values tested were within $\pm 50 \%$ of the calibrated values obtained by [17]. Each of the 25 events extracted from the monitored data were simulated with these 1000 sets of parameter values.

There are many alternative calibration metrics that can be used to test the suitability of a set of parameter values. As the purpose of the calibration is to use the model to predict flow sequences for use with an At-Site Flood Frequency, the absolute value of the normalised peak flow error was used as the calibration metric. This can be expressed as:

$$
\varepsilon=\left|\frac{\left(Q_{p}-Q_{r}\right)}{Q_{r}}\right|
$$

where $\varepsilon$ is the absolute value of the normalised peak flow error, and $Q_{p}$ and $Q_{r}$ are the peak flows of the predicted and recorded flow hydrographs. This calibration metric was determined for the predicted hydrographs resulting from use of the 1000 alternative datasets with the 25 extracted events.

Shown in Figure 3 and Figure 4 are representative predicted and recorded hydrographs; the predicted hydrographs shown are the best dataset for that event as defined by the normalised peak flow error. The importance of the rainfall model on the reliability of the predicted hydrographs can be seen in the April 1989 event hydrographs (Figure 4) where the recorded rainfall at the gauging station is not representative of the rainfall over the catchment; [23] and [24] discuss rainfall models in more detail and their importance in the simulation of fast responding urban catchments. Since the aim of the catchment modelling is the prediction of peak flows for use in an At-Site Flood 
6 of 10

Frequency Analysis, errors in the prediction of the occurrence time were not considered sufficient justification for deletion of the event from those considered; in most cases, a simple time-shift in the precipitation resulted in convergence of the predicted and recorded hydrographs.

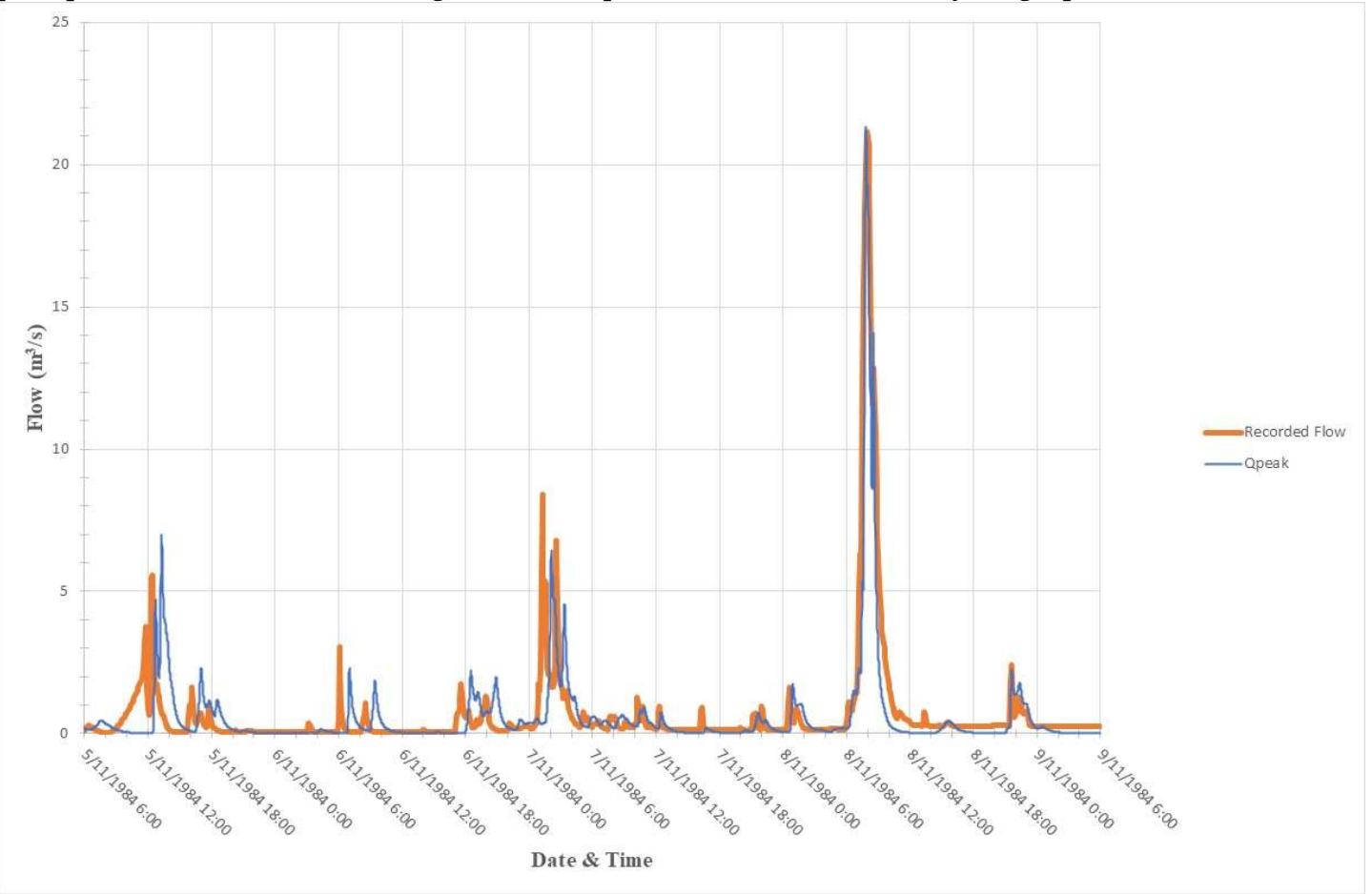

Figure 3. November 1984 Event

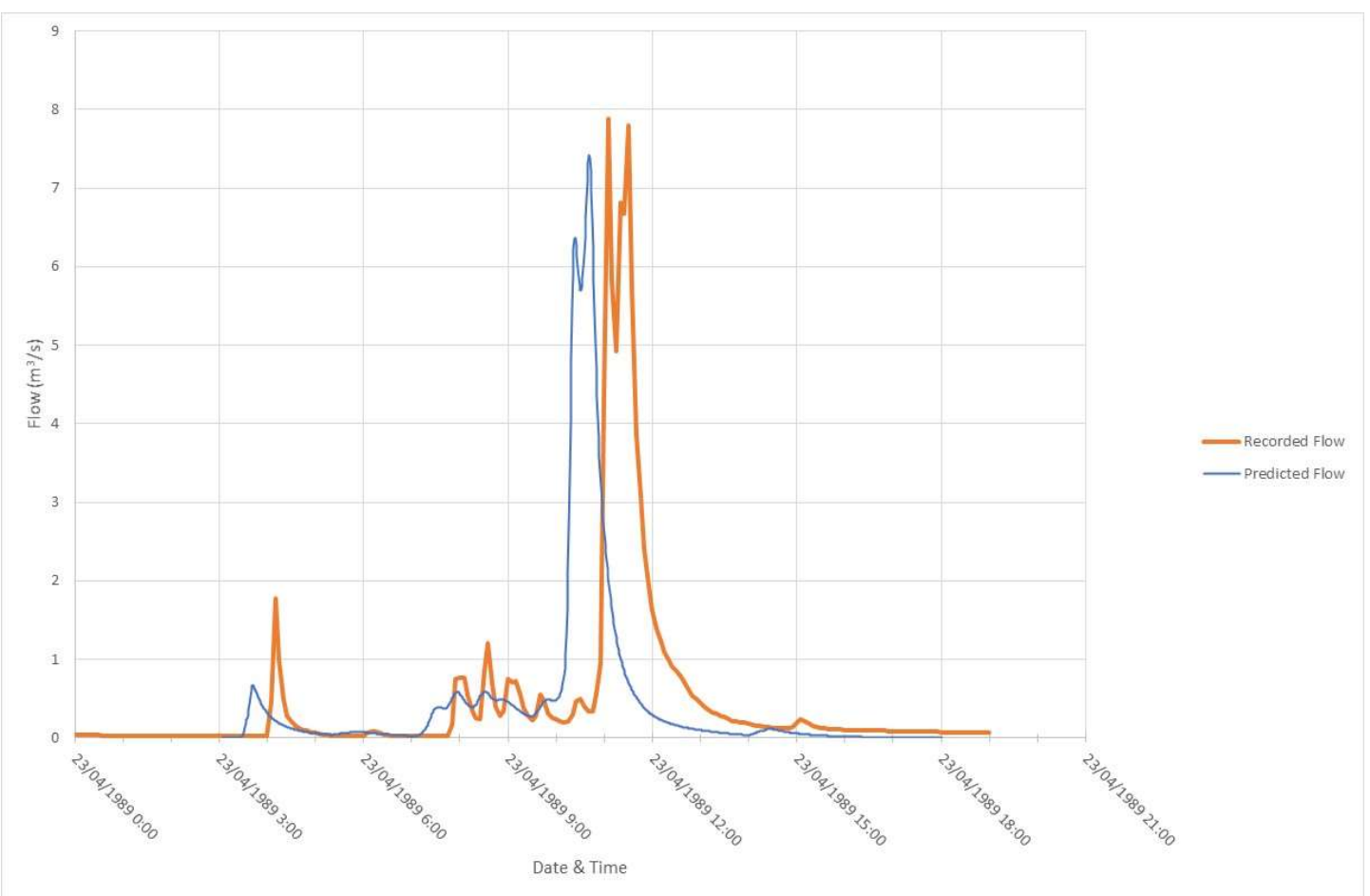

Figure 4. April 1989 Event

Five alternative values for the normalised peak flow error were considered; these were 5, 10, 15, 20 , and $25 \%$ errors. For each event, the number of parameter sets resulting in the normalised peak 
flow error being less than the specified limit were counted. Shown in the second column of Table 4 are the average number of datasets less than the specified limit when all extracted events are considered; in other words, for a normalised peak flow error of 5\%, an average of 146 datasets per event resulted in satisfaction of the criterion. As expected, relaxation of the criterion results in an increased number of datasets satisfying the criterion. Relaxing the allowed error from $5 \%$ to $25 \%$ resulted in the proportion of datasets having a normalised peak flow error satisfying the criterion increasing from $15 \%$ to $72 \%$ of the 1000 available datasets.

Table 4. Peak Flow Prediction Accuracy

\begin{tabular}{cccc}
\hline $\begin{array}{c}\text { Normalised Peak Flow } \\
\text { Error } \\
(\%)\end{array}$ & $\begin{array}{c}\text { Average Number of } \\
\text { Datasets }\end{array}$ & Best Dataset & $\begin{array}{c}\text { Proportion of } \\
\text { Events } \\
(\%)\end{array}$ \\
\hline 5 & 146 & 308 & 48 \\
10 & 297 & 308 & 72 \\
15 & 459 & 431 & 80 \\
20 & 612 & 20 & 88 \\
25 & 719 & 109 & 92 \\
\hline
\end{tabular}

In addition to determining the number of datasets satisfying the criterion, the normalised peak flow error for each dataset and event were determined and the dataset with the highest number of events satisfying the criterion determined. For the criteria considered, these datasets and the proportion of events with satisfaction of the criterion are shown in the third and fourth columns of Table 4 respectively. While 5 values of the criterion were considered, only 4 alternative datasets were identified as the same dataset provided the best performance for the $5 \%$ and $10 \%$ error criteria.

Shown in Figure 5 are the peak flows predicted using these datasets for the events considered. No obvious trends in the predictions are apparent in Figure 5. As poor predictions of a particular event are replicated in all 4 datasets, it is likely that these events have poor rainfall representation over the catchment.

\subsection{Flood Frequency Analysis}

The 4 selected datasets were used with precipitation records for the period 1981-1990 (i.e. a 10 year period) to generate flow data at the gauging station. Annual Maxima Series were extracted from these records and At-Site Flood Frequency Analyses (see Figure 6) were undertaken using the approaches outlined in [25]. In particular, the statistical model used was an LPIII with parameters estimated using Bayesian techniques. Shown in Figure 6 are the resultant peak flow likelihoods arising from the monitored (recorded) data and the selected 4 datasets.

While the predicted quantiles from all 4 datasets fit within the $90 \%$ confidence limits, it is apparent that design flood predictions using dataset 308 more closely replicate those obtained from the recorded data than those from the other datasets. Shown in Table $\mathbf{5}$ is a comparison between the design flood quantiles estimated from the monitored data and the 4 selected datasets. Also shown in this table are the variations in design flood quantiles when compared with those for the monitored data. Consistent with the trends shown in Figure 6, the design flood quantiles obtained using dataset 308 had the smallest variation.

Dataset 308 resulted in $48 \%$ of the peak flow predictions occurring within $5 \%$ of the recorded peak flow, and $72 \%$ of the peak flow predictions occurring within $10 \%$ of the recorded peak flow. An alternative dataset (i.e. dataset 431 ) had a greater number of peak flow predictions within $15 \%$ of the recorded peak flow. Hence, it can be concluded that reliable estimation of design flood quantiles using At-Site Flood Frequency Analyses requires the calibration metric of individual events to be within $10 \%$ of the recorded. 


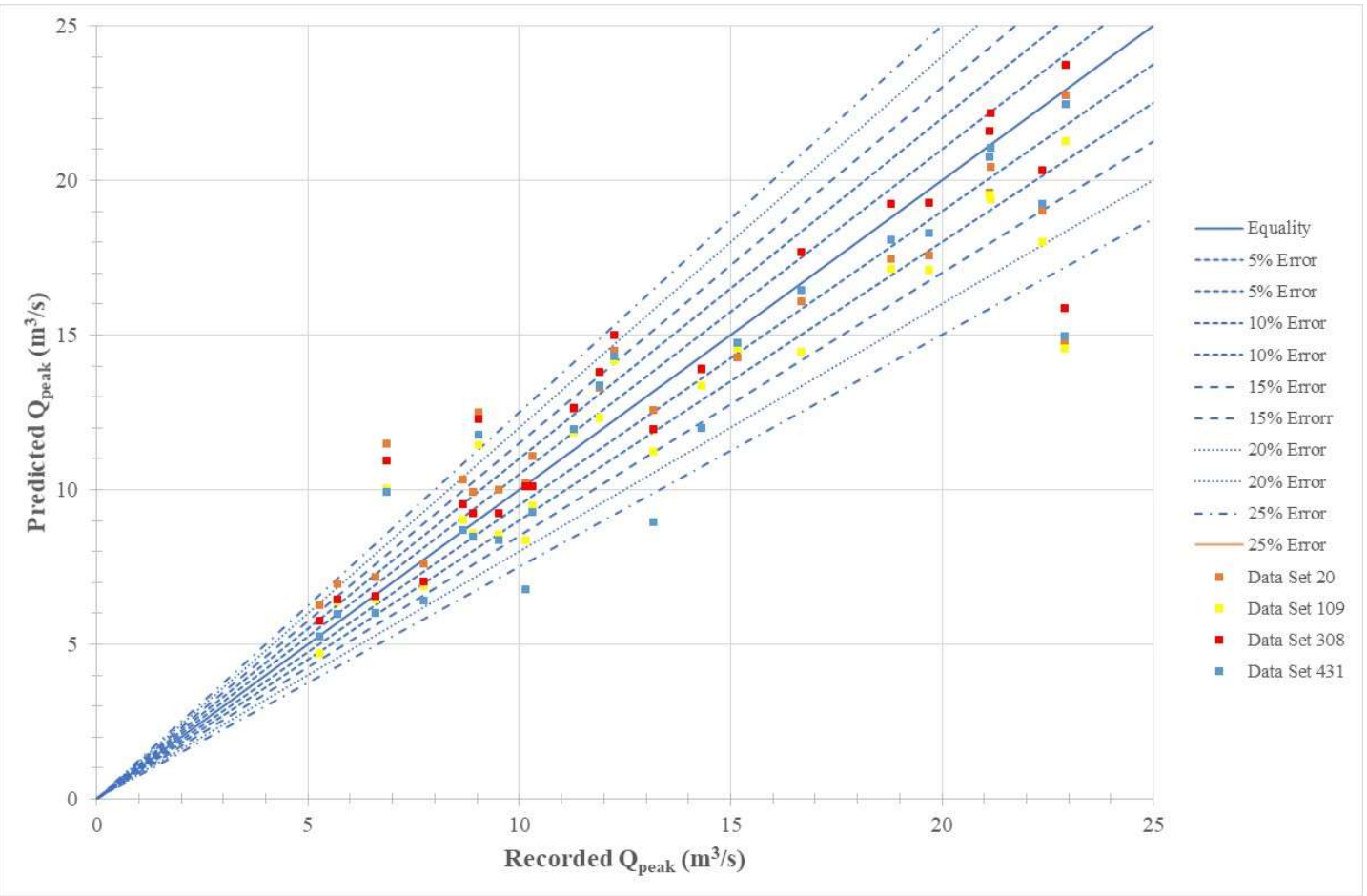

Figure 5. Predicted Peak Flow vs Recorded Peak Flow for the Selected Datasets

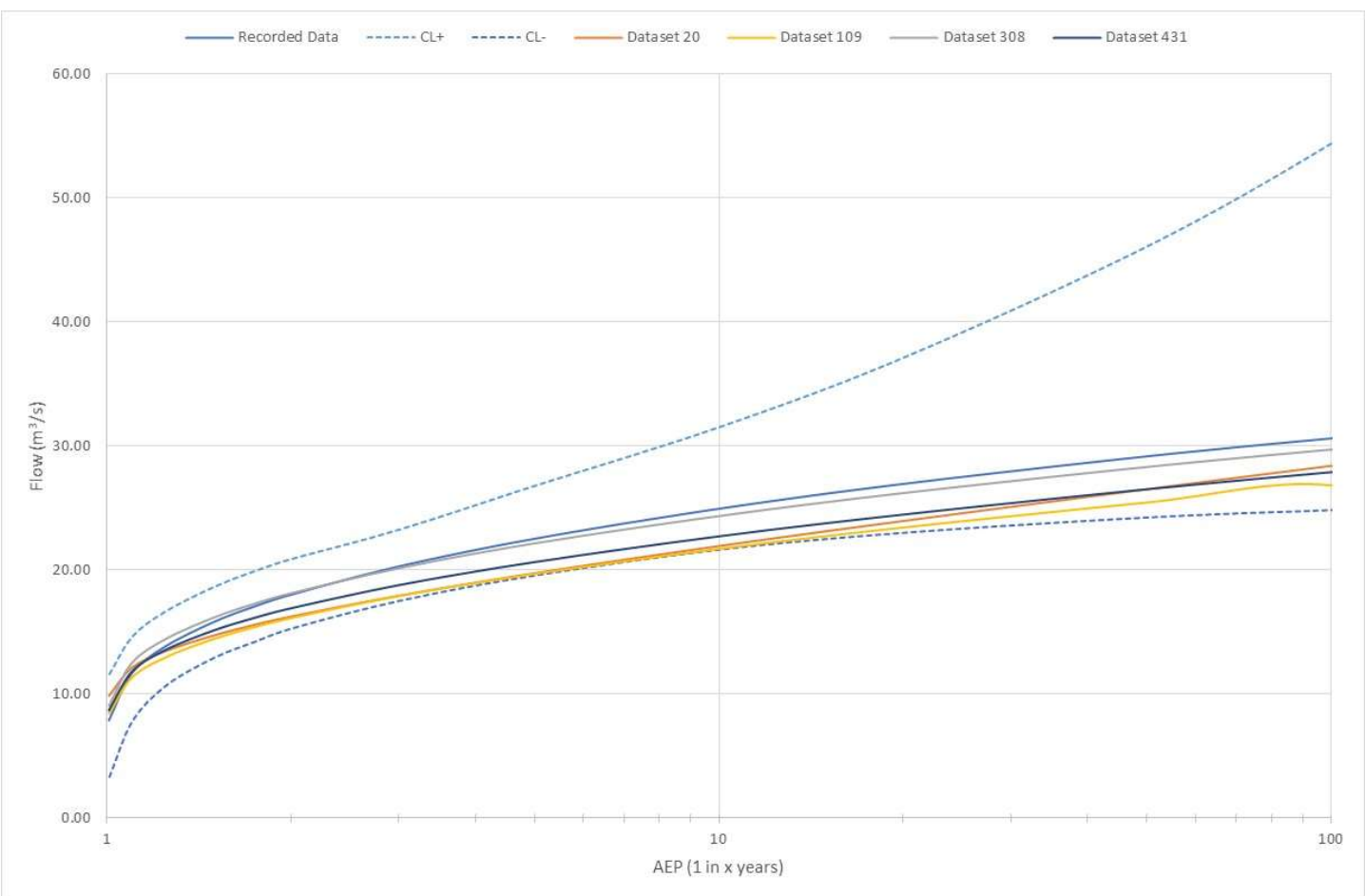

Figure 6. FFA using Selected Datasets 
Table 5. Design Flood Quantiles

\begin{tabular}{|c|c|c|c|c|c|c|c|c|c|}
\hline \multirow{3}{*}{$\begin{array}{c}\text { AEP } \\
(1 \text { in } x \\
\text { years }) \\
5\end{array}$} & \multirow{3}{*}{$\begin{array}{c}\begin{array}{c}\text { Monitored } \\
\text { Data } \\
\left(\mathrm{m}^{3} / \mathrm{s}\right)\end{array} \\
22.5\end{array}$} & \multicolumn{8}{|c|}{ Dataset } \\
\hline & & \multicolumn{2}{|c|}{$\begin{array}{c}20 \\
\left(\mathrm{~m}^{3} / \mathrm{s}\right)\end{array}$} & \multicolumn{2}{|c|}{$\begin{array}{c}109 \\
\left(\mathrm{~m}^{3} / \mathrm{s}\right)\end{array}$} & \multicolumn{2}{|c|}{$\begin{array}{c}308 \\
\left(\mathrm{~m}^{3} / \mathrm{s}\right)\end{array}$} & \multicolumn{2}{|c|}{$\begin{array}{c}431 \\
\left(\mathrm{~m}^{3} / \mathrm{s}\right)\end{array}$} \\
\hline & & 19.7 & $-12.4 \%$ & 19.7 & $-12.4 \%$ & 22.1 & $-1.8 \%$ & 20.6 & $-8.4 \%$ \\
\hline 10 & 24.9 & 21.9 & $-12.0 \%$ & 21.7 & $-12.9 \%$ & 24.4 & $-2.0 \%$ & 22.7 & $-8.8 \%$ \\
\hline 20 & 26.7 & 24.0 & $-10.1 \%$ & 23.4 & $-12.4 \%$ & 26.2 & $-1.9 \%$ & 24.4 & $-8.6 \%$ \\
\hline 100 & 30.6 & 28.4 & $-7.2 \%$ & 26.8 & $-12.4 \%$ & 29.7 & $-2.9 \%$ & 27.9 & $-8.8 \%$ \\
\hline
\end{tabular}

\section{Conclusions}

Estimating floods in urban catchments is a complex task that is complicated by the lack of reliable data. To circumvent this data deficiency, data from catchment models commonly is used. Calibration of the catchment model will influence the reliability of this data. An analysis of the calibration accuracy has been presented. The calibration metric considered was a normalised peak flow error for individual events. From 1000 alternative sets of parameter values, the dataset with the greatest number of peak flow predictions less than the acceptance criterion was used to generate a 10-year flow sequence which was used for an At-Site Flood Frequency Analysis. Alternative acceptance criteria, i.e. 5, 10, 15, 20 and 25\% errors were considered and it was found that the dataset selected for the $5 \%$ and $10 \%$ error criteria (the same dataset was selected for both criteria) provided design flood quantiles with the lowest variation from those obtained using the historical data. Therefore, it was concluded that the maximum acceptable calibration error was a $10 \%$ error in the normalised peak flow.

\section{References}

1. Affairs, U.D.o.E.a.S. www.un.org/development/desa/en/news/population/2018-revision-of-world-urbanizationprospects.html. 20182 October 2020].

2. Andimuthu, R., et al., Performance of urban storm drainage network under changing climate scenarios: Flood mitigation in Indian coastal city. Sci Rep, 2019. 9(1): p. 7783.

3. Audisio, C. and L. Turconi, Urban floods: a case study in the Savigliano area (North-Western Italy). Natural Hazards and Earth System Sciences, 2011. 11(11): p. 2951-2964.

4. Hettiarachchi, S., C. Wasko, and A. Sharma, Increase in flood risk resulting from climate change in a developed urban watershed - the role of storm temporal patterns. Hydrology and Earth System Sciences, 2018. 22(3): p. 2041-2056.

5. Smithers, J.C., Methods for design flood estimation in South Africa. Water SA, 2012. 38(4).

6. Ball, J.E., URBAN FLOOD MODELLING - PROCESS OR REGRESSION?, in 37th IAHR World Congress. 2017: Kuala Lumpur, Malaysia.

7. Bates, B.C. and L.R. Townley, Nonlinear Discrete Flood Event Models, 1. Bayesian Estimation of Parameters. Journal of Hydrology, 1988. 99: p. 61 - 76.

8. Kuczera, G., et al., Towards a Bayesian total error analysis of conceptual rainfall-runoff models: Characterising model error using storm-dependent parameters. Journal of Hydrology, 2006. 331(1-2): p. 161-177.

9. Hendrickson, J.D., S. Sorooshian, and L.E. Brazil, Comparison of Newton-Type and Direct Search Algorithms for Calibration of Conceptual Rainfall-Runoff Models. Water Resources Research, 1988. 24(5): p. 691 - 700.

10. Wang, Q., The Genetic Algorithm and Its Application to Calibrating Conceptual Rainfall-Runoff Models. Water Resources Research, 1991. 27(9): p. 5.

11. Fang, T. and J. Ball, Investigation of parameter interactions in a physically distributed catchment modelling system, in Proceedings 31st Hydrology and Water Resources Symposium (Water Down Under 2008). 2008. 
12. Duan, Q., S. Sorooshian, and V. Gupta, Effective and Efficient Global Optimization for Conceptual RainfallRunoff Models. Water Resources Research, 1992. 28(4): p. 1015 - 1031.

13. Parsopoulos, K. and M. Vrahatis, Parameter selection and adaption in unified particle swarm optimization. Mathematical and Computer Modelling, 2007. 46: p. \%D 198-213.

14. Lettenmaier, D. and E. Wood, Hydrological forecasting, in Handbook of hydrology, D. Maidment, Editor. 1993, McGraw-Hill: New York, USA.

15. Gupta, H.V., et al., Decomposition of the mean squared error and NSE performance criteria: Implications for improving hydrological modelling. Journal of Hydrology, 2009. 377(1-2): p. 80-91.

16. Jackson, E.K., et al., Introductory overview: Error metrics for hydrologic modelling - A review of common practices and an open source library to facilitate use and adoption. Environmental Modelling \& Software, 2019. 119: p. 32-48.

17. Meutia, E.Z., Development of a catchment modelling system for the Powells Creek Catchment. 2002, Master of Engineering Science Report, School of Civil and Environmental Engineering: The University of New South Wales, Sydney, Australia.

18. Rossman, L.A., Storm Water Management Model User's Manual Version 5.1. 2015, Cincinnati, OH, USA: U.S. Environmental Protection Agency.

19. Leutnant, D., A. Döring, and M. Uhl, swmmr - an R package to interface SWMM. Urban Water Journal, 2019. 16(1): p. 68-76.

20. Broekhuizen, I., et al., Event selection and two-stage approach for calibrating models of green urban drainage systems. Hydrology and Earth System Sciences, 2020. 24(2): p. 869-885.

21. Ball, J., A Review of Numerical Models for Prediction of Catchment Water Quantity and Quality, in Research Report, Water Research Laboratory. 1992, The University of New South Wales: Sydney, Australia.

22. Choi, K.-s. and J.E. Ball, Parameter estimation for urban runoff modelling. Urban Water, 2002. 4(1): p. 31-41.

23. Umakhanthan, K. and J. Ball, Rainfall Models for Catchment Simulation. Australian Journal of Water Resources, 2005. 9(1): p. 55-67.

24. Zhang, J. and D. Han, Assessment of rainfall spatial variability and its influence on runoff modelling: A case study in the Brue catchment, UK. Hydrological Processes, 2017. 31(16): p. 2972-2981.

25. Ball, J., et al., Australian rainfall and runoff: a guide to flood estimation. 2016: Commonwealth of Australia, Geoscience Australia. 